\title{
POTENCIAL DE REMOÇÃO DE AZUL DE METILENO UTILIZANDO BAGAÇO DE MALTE IN NATURA POR MEIO DE PLANEJAMENTO FATORIAL $2^{2}$
}

\author{
R. C. A. LIMA ${ }^{1}$, K. ZAPELÃO ${ }^{1}$, D. F. S. PARLADORE ${ }^{1}$ e A. ANSCHAU ${ }^{1}$ \\ ${ }^{1}$ Universidade Tecnológica Federal do Paraná, Engenharia Bioprocessos e Biotecnologia \\ E-mail para contato: andreiaanschau@utfpr.edu.br
}

\begin{abstract}
RESUMO - Buscando analisar os efluentes das indústrias têxteis, o objetivo deste trabalho foi avaliar o bagaço de malte como adsorvente do corante azul de metileno. Foi feito um Planejamento Fatorial $2^{2}$ onde foram estudadas diferentes granulometrias de bagaço de malte (20, 40 e 60 mesh) e $\mathrm{pH}$ da solução de corante $(3,0,6,0$ e 9,0). Os resultados obtidos a partir do Planejamento Fatorial foram avaliados estatisticamente por análise de variância (ANOVA) e teste Tukey, de forma a identificar diferenças com significância estatística na porcentagem de remoção do corante azul de metileno e na quantidade de corante absorvida pelo bagaço de malte. Todos os experimentos resultaram em remoção acima de $90 \%$ de corante. Através do Teste de Tukey, observou-se que não houve diferença estatisticamente significativa na entre os pontos centrais (40 mesh; $\mathrm{pH}_{-} 6$ ). A partir da curva de contorno, verifica-se que a maior remoção de azul de metileno ocorre utilizando granulometria maior e em pH acima da neutralidade. É possível verificar que a granulometria apresentou maior influência na remoção de corante do que $\mathrm{pH}$, o que já havia sido comprovado na ANOVA. Os próximos estudos serão feitos com granulometria intermediária (40 mesh) e $\mathrm{pH}$ 6,65, definido anteriormente a partir da análise do ponto de carga zero do bagaço de malte. Este fato é vantajoso uma vez que a necessidade de ajuste de $\mathrm{pH}$ de um efluente demandaria de tempo e reagentes químicos que podem encarecer o processo.
\end{abstract}

\section{INTRODUÇÃO}

Segundo Mello (2014) a caracterização da biomassa é quem determina a escolha do processo de conversão e as dificuldades de processamento subsequentes que possam surgir. Para se caracterizar biomassa devem-se conhecer suas propriedades físicas e sua composição química. A utilização de biomassas se enquadra perfeitamente no conceito de desenvolvimento sustentável, além de reduzir custos e não agredir o meio ambiente (Cordeiro, 2011).

Durante a produção de cerveja gera-se um resíduo que é considerado um subproduto industrial com baixo valor agregado e é resultante da fase inicial do processo como uma fração sólida de malte de cevada remanescente após a produção de mosto, denominado de bagaço de malte de acordo com Stojceska \& Ainsworth (2008); Waters et al. (2012)

A adsorção é uma operação unitária que envolve o contato entre uma fase fluida e uma sólida, originando uma transferência de massa da fase fluida para a superfície do sólido 
ocorrendo uma tendência de acúmulo de uma substância (adsorvato) sobre a superfície da outra (adsorvente) (McCABE et al., 2001).

De acordo com Dallago et. al, (2005) atualmente o material que apresenta maior capacidade de adsorção, sendo amplamente utilizado para o tratamento de efluentes, é o carvão ativado. Entretanto, devido às perdas durante o processo de recuperação do adsorvente, sua utilização torna-se onerosa. Neste sentido, existe um crescente interesse pela busca de materiais alternativos de baixo custo que possam ser utilizados, em substituição ao carvão ativado, como adsorventes para a eliminação de corantes têxteis, tais como argilas, bagaço de cana, madeira e outros resíduos celulósicos.

Neste experimento, foi utilizado o bagaço de malte in natura, subproduto da indústria cervejeira com o objetivo de avaliar sua capacidade de adsorção do corante azul de metileno.

\subsection{Materiais e Métodos}

Adsorvente: $\mathrm{O}$ bagaço de malte foi cedido pela micro cervejeira Schaf Bier, localizada na cidade de Francisco Beltrão, Paraná, Brasil. Para o preparo do bagaço de malte, o mesmo foi submetido à lavagem com água corrente, para a remoção das impurezas, seguido de secagem em estufa. Após, foi feita a moagem dos grãos utilizando um moinho de facas, para obtenção de diferentes granulometrias (20, 40 e 60 mesh).

Planejamento Fatorial Completo 22: Para estudar o efeito da granulometria (20, 40 e 60 mesh) e do $\mathrm{pH}(3,0 ; 6,0 ; 9,0)$, foi feito um Planejamento Fatorial Completo $2^{2}$, com 3 pontos centrais, num total de 7 ensaios. Os ensaios de adsorção em sistema em batelada foram realizados adicionando-se $0,3 \mathrm{~g}$ do adsorvente em $50 \mathrm{~mL}$ de solução de azul de metileno (100 $\mathrm{mg} / \mathrm{L}$ ), em frascos Erlenmeyers de $125 \mathrm{~mL}$, resultando em uma dosagem de adsorvente de 6 $\mathrm{g} / \mathrm{L}$ em base seca. Todos os ensaios foram feitos em triplicata e o $\mathrm{pH}$ ajustado para os respectivos ensaios. Os Erlenmeyers foram mantidos em Shaker a $30^{\circ} \mathrm{C}, 100 \mathrm{rpm}$ durante 20 horas. Após, as amostras foram centrifugadas e quantificadas quanto à porcentagem de remoção de corante através de análises em triplicata em espectrofotômetro a $665 \mathrm{~nm}$, a partir de uma curva de calibração.

Equilíbrio de adsorção: A quantidade de corante adsorvida no equilíbrio foi calculada utilizando-se a Equação 1 sendo que qeq é a quantidade de corante adsorvida no equilíbrio $(\mathrm{mg} / \mathrm{g}), \mathrm{C}_{0}$ é a concentração inicial de corante na fase líquida $(\mathrm{mg} / \mathrm{L}), \mathrm{C}_{\text {eq }}$ a concentração de corante na fase líquida no equilíbrio $(\mathrm{mg} / \mathrm{L}), \mathrm{V}$ o volume da solução de corante (L) e $\mathrm{m}$ a massa de bagaço de malte in natura (g).

$$
q e q=[(C o-C e q) x V] m
$$


Análise estatística: Os resultados dos ensaios do Planejamento Fatorial foram analisados estatisticamente, utilizando-se o software STATISTICA 7.0 (Analytical Software, Tallahassee, FL, USA). Foi feita a verificação dos efeitos individuais e de interação das variáveis sobre cada resposta, definição das variáveis importantes para o processo, avaliação dos erros experimentais e para a modelagem empírica dos resultados em função das variáveis escolhidas. Efetuou-se Análise de Variância (ANOVA) e a comparação de médias foi feita pelo teste de Tukey a 5\% de probabilidade de erro.

\subsection{Resultados e Discussão}

Na Tabela 1 são apresentados os níveis codificados e reais das variáveis estudadas com os resultados de porcentagem de remoção do corante após 20 horas.

Tabela 1 - Matriz dos ensaios do Planejamento Fatorial $2^{2}$ e porcentagem de remoção do corante após 20 horas

\begin{tabular}{cccc}
\hline Ensaio & $\begin{array}{c}\text { Granulometria } \\
(\text { mesh })\end{array}$ & pH & $\begin{array}{c}\text { Remoção } \\
(\%)\end{array}$ \\
\hline 1 & $-1(60)$ & $-1(3)$ & $92,5 \pm 0,21^{\mathrm{a}}$ \\
2 & $+1(20)$ & $-1(3)$ & $95,2 \pm 0,23^{\mathrm{b}}$ \\
3 & $-1(60)$ & $+1(9)$ & $91,3 \pm 0,26^{\mathrm{c}}$ \\
4 & $+1(20)$ & $+1(9)$ & $96,7 \pm 0,31^{\mathrm{d}}$ \\
5 & $0(40)$ & $0(6)$ & $95,7 \pm 0,44^{\mathrm{b}}$ \\
6 & $0(40)$ & $0(6)$ & $95,3 \pm 0,53^{\mathrm{b}}$ \\
7 & $0(40)$ & $0(6)$ & $95,5 \pm 0,26^{\mathrm{b}}$ \\
\hline
\end{tabular}

A quantidade de corante adsorvida no equilíbrio variou de 15,2 a $16,1 \mathrm{mg} / \mathrm{g}$ para todas as condições estudadas. Os resultados obtidos foram avaliados estatisticamente pelo Teste de Tukey, de forma a identificar diferenças com significância estatística na porcentagem de remoção do corante azul de metileno e na quantidade de corante absorvida pelo bagaço de uva de malte.

Os resultados indicaram que os ensaios 1, 3 e 4 diferiram entre si e entre os demais ensaios na remoção do corante. Esta diferença foi considerada estatisticamente significativa segundo o Teste de Tukey a 95\% de confiabilidade. Os ensaios 2, 5, 6, e 7 não apresentaram diferença estatisticamente significativa. Esse resultado já era esperado visto que os ensaios 5, 6 e 7 representam os pontos centrais do Planejamento Fatorial $2^{2}$. Além disso, os ensaios 2 e 4 , feitos com a mesma granulometria, mas diferindo no $\mathrm{pH}$, mostram uma remoção de azul entre $95 \%$ e $96 \%$ respectivamente, mostrando que o $\mathrm{pH}$ não influenciou significativamente na remoção do corante. 
Fez-se Análise de Variância (ANOVA) considerando significativos os parâmetros com p-valores menores que 5\% ( $\mathrm{p}<0,05)$. A Tabela 2 apresenta a análise de variância (ANOVA).

A correlação matemática entre a resposta analítica e as variáveis foi realizada por regressão linear e checagem de curvatura. Através da checagem de curvatura, o software estima se há diferença significativa na inclinação entre as duas possíveis retas formadas entre o nível inferior e o ponto central e entre o ponto central e o nível superior.

A partir dos resultados da análise estatística checando a curvatura constatou-se que somente o pH não foi estatisticamente significativo ao nível de confiança de $95 \%$. O valor de

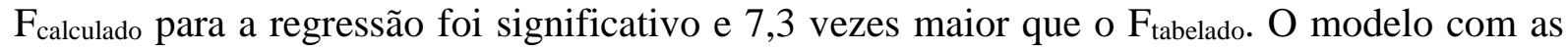
variáveis codificadas que representa a porcentagem de remoção de corante em função da granulometria e do $\mathrm{pH}$ está mostrado na Equação 2, onde $\mathrm{X}_{1}=$ granulometria (mesh) e $\mathrm{X}_{2}=$ $\mathrm{pH}$.

$$
\% \text { Remoção }=93,9+1,01 X_{1}+0,03 X_{2}+0,34 X_{1} X_{2}
$$

Tabela 2 - ANOVA da remoção de azul de metileno

\begin{tabular}{ccccc}
\hline FV & SQ & GL & QM & Falc $_{\text {can }}$ \\
\hline Regressão & 22,50 & 4 & 5,63 & 140,75 \\
Resíduos & 0,08 & 2 & 0,04 & \\
Total & 22,58 & 6 & &
\end{tabular}

FV: fonte de variação, SQ: soma dos quadrados, GL: graus de liberdade, QM: quadrado médio, $\mathrm{R}^{2}:$ 99,81 , $\mathrm{F}_{4,2} ; 0,05: 19,25$

A porcentagem de variação explicada $\left(\mathrm{R}^{2}\right)$ pelo modelo foi muito boa $(99,81 \%)$, sendo que o modelo de primeira ordem se ajusta bem aos dados experimentais, podendo-se assim, construir a superfície de resposta e definir as regiões de interesse. Através da superfície de resposta gerada pelo modelo como mostra na Figura 1, pode-se obter o $\mathrm{pH}$ e a granulometria que resultam na melhor remoção do azul de metileno.

Analisando a figura observou-se que a maior remoção de azul de metileno ocorre utilizando granulometria maior e em $\mathrm{pH}$ acima da neutralidade. É possível verificar que a granulometria apresentou maior influência na remoção de corante do que pH, o que já havia sido comprovado na ANOVA.

Figura 1 - (a) Superfície de resposta e (b) curva de contorno em função da granulometria e pH para a remoção de azul de metileno pelo bagaço de malte in natura. 


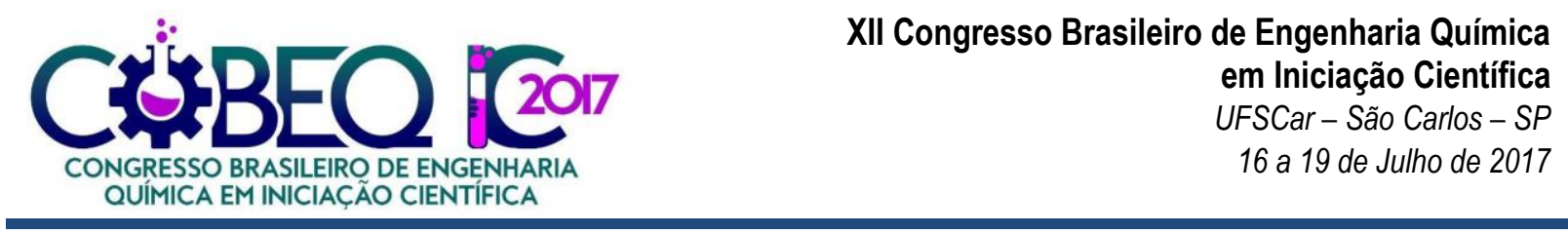

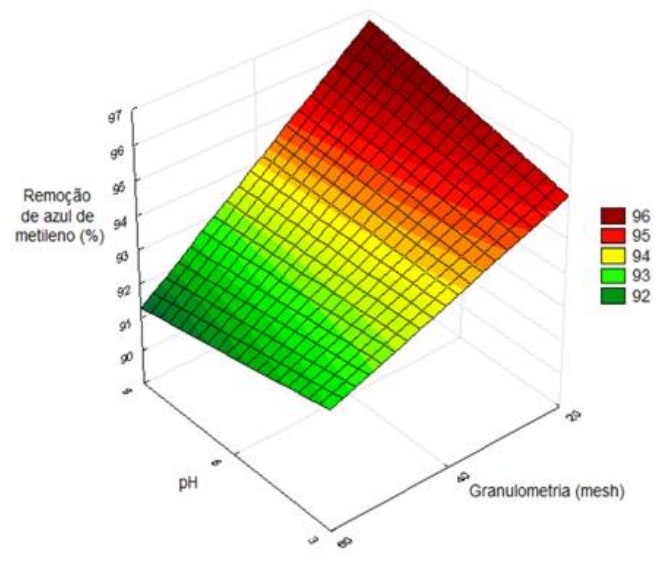

(a)

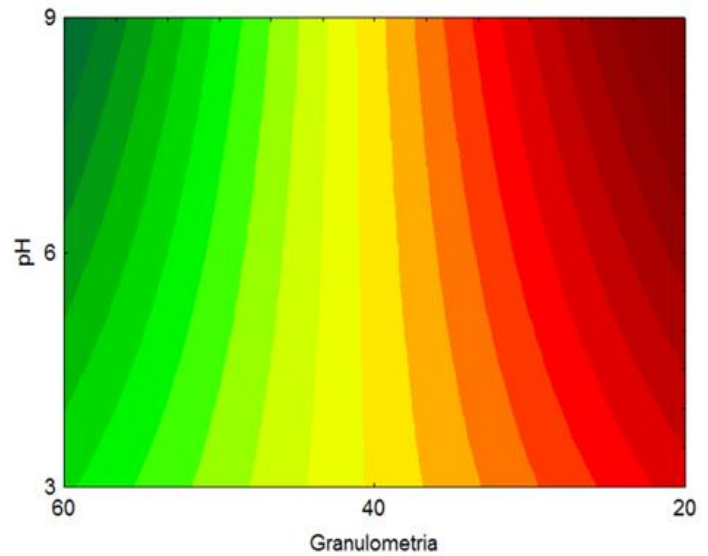

(b)

Santos (2013) observou que a melhor descoloração das amostras com azul de metileno a partir da casca de café ocorreu com pH 3, à $230 \mathrm{rpm}, 45^{\circ} \mathrm{C}$, obtendo $60,4 \%$ de remoção de corante, e o equilíbrio só foi atingido depois de 30 horas de adsorção. No trabalho de Stroher $e t$ al. (2012) apesar do bagaço de laranja apresentar uma grande capacidade de adsorver o efluente, o pH teve de ser ajustado em 3 para obter maior remoção de cor pelo bagaço de laranja e o tempo de contato adsorvente/efluente determinado foi de 50 horas.

Mazetto et al. (2016) obteve remoção de azul de metileno acima de $94 \%$ utilizando biomassa de uva-do-Japão in natura, estudando as mesmas faixas de granulometrias e $\mathrm{pH}$. Nakamura et al. (2010) mostrou que o carvão ativado produzido a partir de bagaço de malte apresentou descoloração da solução de azul de metileno a $200 \mathrm{mg} / \mathrm{L}$ de 99,97\% em apenas 6 horas, a partir dos resultados obtidos neste trabalho, pôde-se verificar que o bagaço de malte seco se apresentou como matéria-prima de grande potencial para a produção de carvão ativado.

A partir do exposto, verifica-se que o bagaço de malte é apropriado para o processo de remoção corante, mostrando-se eficiente na remoção de corante em $\mathrm{pH}$ neutro, evitando assim um pré-tratamento químico nos efluentes para atingir meio ácido.

\section{CONCLUSÃO}

$\mathrm{O}$ bagaço de malte pode ser considerado um adsorvente promissor, por ser um material abundante, de baixo custo e eficiente na remoção do corante azul de metileno. Como todos os ensaios do Planejamento Fatorial resultaram em alta porcentagem de remoção de corante e alta quantidade adsorvida, os próximos estudos serão feitos com granulometria intermediária (40 mesh) e pH 6,65, definido previamente a partir da análise do ponto de carga zero do bagaço de malte. Este fato é vantajoso uma vez que a necessidade de ajuste de $\mathrm{pH}$ de um efluente demandaria de tempo e reagentes químicos que podem encarecer o processo.

\section{REFERENCIAS}

CORDEIRO, L. G. Caracterização e Viabilidade Econômica do Bagaço de Malte Oriundo de Cervejarias para Fins Energéticos. Dissertação de Mestrado. Universidade Federal da 
Paraíba, 2011.

DALLAGO, R. M.; SMANIOTTO, A.; OLIVEIRA, L. D. Resíduos sólidos de curtumes como adsorventes para a remoção de corantes em meio aquoso. Química Nova, 28(3), 433437. 2005 .

GONÇALVES, G. C.; NAKAMURA, P. K.; VEIT, M. T.; FIAMETTI, K.G.; SILVA, G. M. C. Produção E Caracterização De Carvão Ativado Granulado E Bio-Óleo a Partir Dos Resíduos Da Industria Cervejeira. XX COBEQ, p. 1-9, 2010.

GUARATINI, C. C. I.; ZANONI, M. V. B. Corantes Têxteis. Química Nova, Araraquara, p.7179, 31 mar. 1999.

MAZETTO, I. A.; ANSCHAU, A.; BICUDO, M. O. P. Avaliação da capacidade adsorvente do psdeudofruto in natura de uva-do-japão (Hovenia dulcis Thunberg). Revista de Ciências Farmacêuticas Básica e Aplicada, v. 37, n. 9652, p. 100-101, 2016.

McCABE, W. L.; SMITH, J. C.; HARRIOT, P. Unit Operations of Chemical Enginnering. NewYork: McGraw Hill International Ed.; 6th ed., 2001.

MELLO, V. S. de A. Determinação da composição do bagaço do malte de cevada e estudo das suas potenciais aplicações, 2014.

SANTOS, D. F. DOS. Tratamento de Efluente Têxtil Utilizando a Técnica de Adsorção em Casca de Café. Universidade Tecnológica Federal do Paraná - Apucarana, p. 44, 2013.

STOJCESKA, V.; AINSWORTH, P. The effect of different enzyme son the quality of high-fibre enriched brewer's spentgrain breads. Food Chemistry, v.110, p.865-872, 2008.

STROHER, A. P.; MENEZES, M. L.; FIORENTIN, L. D.; PEREIRA, N. C. Utilização do Bagaço de Laranja no Tratamento de Efluente Proveniente da Lavagem de Jeans. EXacta, v. 5, n. 1984, p. 27-37, 2012.

WATERS, D.M. et al. Fibre, protein and mineral fortification of wheat bread through milled and fermented brewer's spent grain enrichment. European Food Research and Technology, v.235, p.767-778, 2012. 